\title{
Optimized Control Strategy to Adjust the Intelligent Universal Transformer for Integrating Distributed Resources to Grid
}

\author{
Maryam Sadeghi* and Majid Gholami \\ Department of Electrical Engineering, Islamic Azad University, Islamshahr Branch, \\ Islamshahr, Iran; sadeghi@iiau.ac.ir
}

\begin{abstract}
Intelligent Universal Transformer (IUT) is a smart multi functional power electronic device will comprise Advanced Distribution Automation (ADA) with new approach in distribution system in future. In contrast to traditional transformers, IUT comes with full monitoring and control functionalities and is controlled by the optimized Genetic Algorithm (GA) for tuning the Membership Functions (MFs) of Fuzzy Logic Controller (FLC). Normally it is the designer concerns to choose the best MFs and expert knowledge is emerged in MFs with no optimization procedure. FLC is non analytic alternative solution for controlling complex applications based on linguistically rules. GA is inspired by natural selection results in survival of strongest individuals in a competitive environment. It employs analogy of natural evolution to find the optimization solutions in highly complex topics. In each replication GA proposes the population of solution so that the value of next population is enhanced due to the last population. This procedure continues till the global optimal solution is occurred. In this approach the IUT application in microgrid for integrating the distributed new resources of energy to power utility is discussed and an optimized FLC fashion is presented for generating the switching pattern for the high frequency inverters of IUT in both Input-Output stages. The proposed optimized FLC together with the IUT topology yields to the smooth control scheme for integrating the microgrid to main grid which will improve the system reliability and performance.
\end{abstract}

Keywords: ADA, DER, IUT, FLC , Microgrid, Renewable Energy Resource

\section{Introduction}

ADA revolutionary modifies traditional distribution systems to wondrous investment in the rate of progress in technology ${ }^{2}$.

It employs flexible electrical architecture with an open communication construction to introduce a novel information exchange model. ADA provides the full automated monitoring and control in each level of its controllable devices. It employs a novel technologies and equipment such as IUT and other Intelligent Electronic Device (IED) for exchanging both data and control among external sources ${ }^{8}$. IUT is a power electronic Multifunctional transformer ${ }^{3,5,10-13,16,18}$ with the outstanding feature of full controllability ${ }^{11,12,19}$. It is based on multilevel converter technology using the High-Voltage Insulated Gate Bipolar Transistor (HV-IGBT) in the high frequency switching pattern ${ }^{4,14}$.

IUT three layers topology $y^{6,7}$ is constructed from seven individual blocks (Figures 1 and 2). First block includes multilevel rectifier (1r) and inverter (1i), rectifies AC input and converts it to square wave.

Second stage comprises DC buses and capacitors. In third block high frequency transformer isolates the voltage.

${ }^{*}$ Author for correspondence 


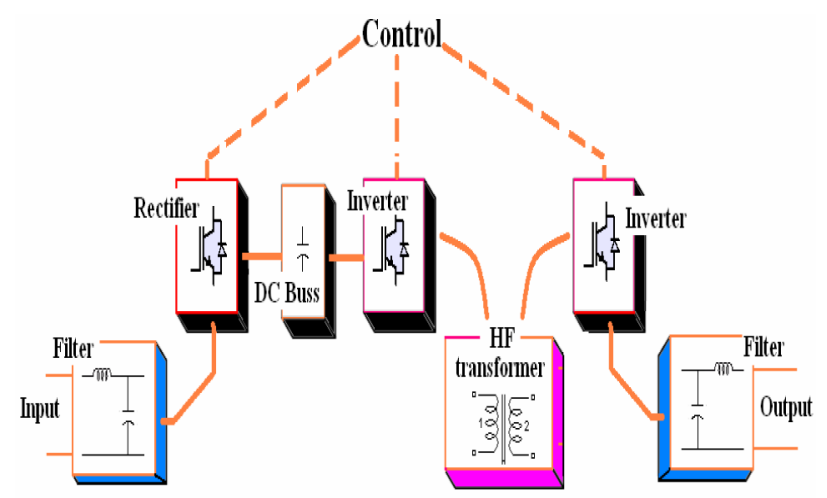

Figure 1. IUT Power electronic construction.

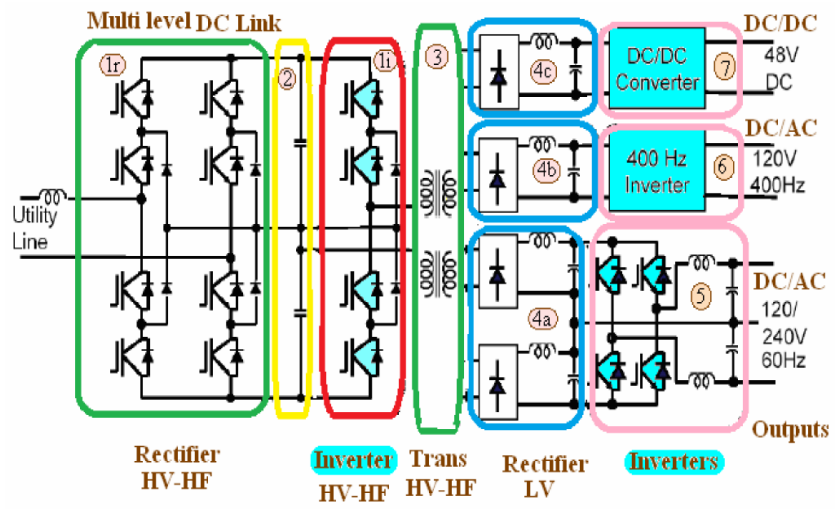

Figure 2. Three level IUT topology including seven blocks.

Rectifiers and filters at fourth stage perform a full bridge inverter to deliver split DC buses. Fifth stage constitutes main inverter of $120 / 240 \mathrm{~V} \mathrm{AC}^{17}$. Then, the auxiliary inverter produces $400-\mathrm{Hz} 120 \mathrm{~V}$ at sixth block. $\mathrm{DC} / \mathrm{DC}$ converter for generating $48 \mathrm{VDC}$ is at last stage.

\section{Microgrid}

Due to the reduction of fossil energy resources and daily increasing power demand and the environment concern, together with the high investment for developing the old transmission and distribution network, using the microgrid is more and more highlighted and seems it is not only a need but an inevitable necessity ${ }^{9,20}$. Microgrid is emerging the distributed resources such as micro turbines, solar photovoltaic, wind and combined heat and power with their associated loads as a subsystem ${ }^{15}$.

Microgrids deliver premium power via the control strategies to capable it to integrate its resources to main grid and provide the smooth reaction when switching to island mode and reconnecting to the power utility. In this case the proposed IUT is a revolutionary solution to provide the most interactive inverter for connecting the microgrid resources to grid with the benefit advantage of reducing the disturbances and providing the minimum Total Harmonic Distortion in grid current and its load.

\section{Optimized FLC}

FLC presented by Lotfi A. Zadeh at Berkeley in 1965. Fuzzy concept defines the intermediate values between the fixed evaluations like true and false, yes and no, etc to uses a human thinking in computer programming. Figure 3 depicts the FLC main concept.

At first, the MFs based on the Man expertise, are reach the stage to replace the crisp values to fuzzified variables. Then FLC finds the outputs related to the predefined linguistically rules that are initiated by expert knowledge. Defuzzification is come to pass in last to substitute the fuzzified outputs to crisp values. Expert knowledge has a decisive role in finding the best MFs. Whatever the expert knowledge looks more and more brilliant the FLC enhances its performance. So GA optimization method empowers FLC to find the most suitable MFs. GA inspired from natural population of living creatures basing on numerical principle.

It is defined by population of binary strings represent the corresponding parameters for simulating gens of chromosome ${ }^{1}$. In the beginning primary population is produced. Afterward fitness evaluation is computed. Finally substrings with the specified length are extracted from the main population. These are the process of genetic selection, crossover and mutation. In this approach the best choices of patterns for forming the FLC MFs equipping GA is presented. In each of iterations, PWM signals of IUT are determined to minimize the Total Harmonic Distortion (THD) (Figure 4).
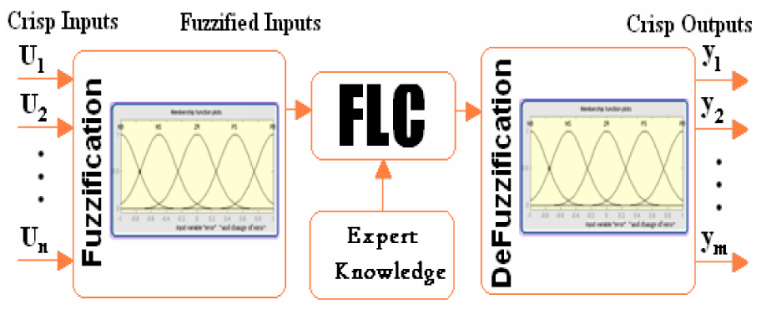

Figure 3. FLC main concept. 


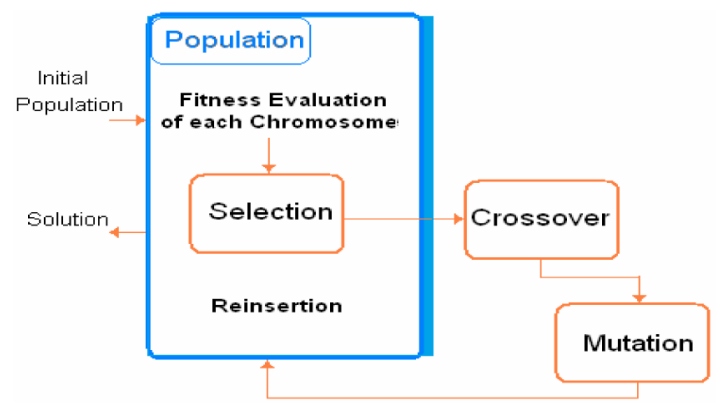

Figure 4. GA sequences.

\section{Control Strategy}

Control strategy is based on generating the high frequency switching pattern for input/output inverters of IUT using optimized FLC by GA (Figures 5 and 6 ).

In primary stage, input current source controller is defined by comparing the IUT input inverter current with reference current and applying the error and its deviation to FLC to hold the input current in phase with voltage and eliminate the harmonic distortion. In output stage, the voltage source controller is defined to adjust the output voltages of inverters in a desired one via optimized FLC.

Error " $\mathrm{e}(\mathrm{t})$ " and change of error "de $(\mathrm{t})$ " providing inputs and duty cycle forms the output of FLC $(\mathrm{u}(\mathrm{t})=$ $\mathrm{F}[\mathrm{e}(\mathrm{t}), \operatorname{de}(\mathrm{t})])$.

Inputs-outputs are mapped by five linguistic values (NB, NS, ZR, PS, PB) which are stand for (negative big, negative small, zero, positive small, positive Big). Corresponding MFs are defined as $\mu_{\mathrm{NB}}, \mu_{\mathrm{NS}}, \mu_{\mathrm{ZO}}, \mu_{\mathrm{PS}}, \mu_{\mathrm{PB}}$. Twenty five rules present the linguistic rules (Figure 7).

In fuzzification part, degree of each linguistic variable is computed for inputs in each cycle through mapping from real to fixed interval $[-1+1]$ using input MFs. $w_{i}$ is weighting factor, computed by minimum fuzzy implication of Mamdani rule acc. to the Eq (1).

$$
w_{i}=\min \left\{\mu_{\mathrm{e}}(\mathrm{e}), \mu_{\mathrm{de}}(\mathrm{de})\right\}
$$

After applying fuzzy inference to each rule, activation level of output (MFs) is take place and through the defuzzification procedure crisp control amount obtains. Realization procedure for function $\mathrm{F}[\mathrm{e}(\mathrm{t}), \mathrm{de}(\mathrm{t})]$ falls out with setting the linguistic values of the scaled inputs $e(t)$ and $\operatorname{de}(\mathrm{t})$ and mapping them to the fuzzy sets. Popular method for is center of area results in the center of profile described by MFs, which are bounded in respective activation level.

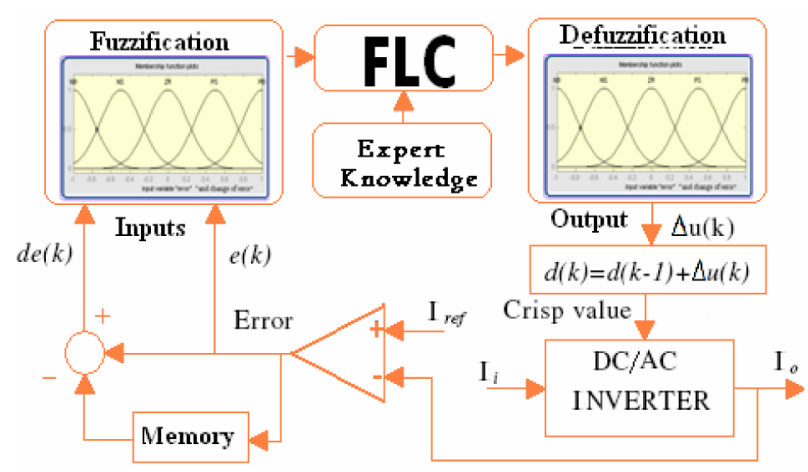

Figure 5. FLC in Input stage of IUT "Current source controller".

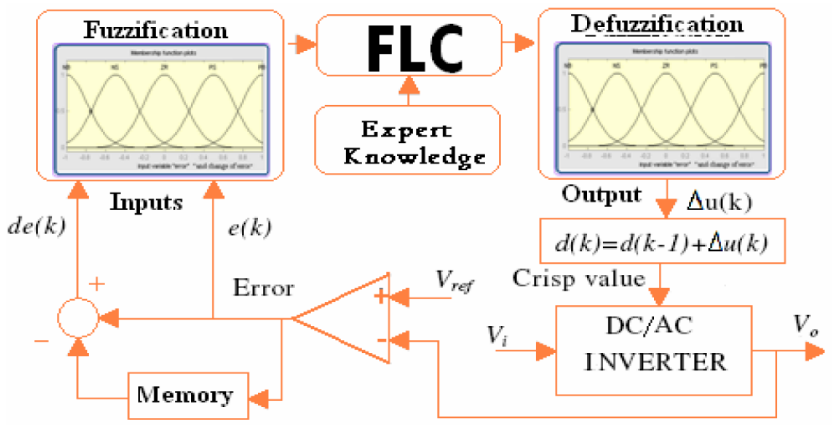

Figure 6. FLC in outputs "voltage source controller".

\begin{tabular}{c|lllll}
\multicolumn{1}{c}{ Control } & & & & \\
\multicolumn{1}{c||}{$e$} & $\mathrm{NL}$ & $\mathrm{NS}$ & $\mathrm{ZR}$ & $\mathrm{PS}$ & $\mathrm{PL}$ \\
\hline $\mathrm{NL}$ & $\mathrm{NL}$ & $\mathrm{NL}$ & $\mathrm{NL}$ & $\mathrm{NL}$ & $\mathrm{NL}$ \\
$\mathrm{NS}$ & $\mathrm{NL}$ & $\mathrm{NM}$ & $\mathrm{NS}$ & $\mathrm{NS}$ & $\mathrm{ZR}$ \\
$\mathrm{ZR}$ & $\mathrm{ZR}$ & $\mathrm{ZR}$ & $\mathrm{ZR}$ & $\mathrm{ZR}$ & $\mathrm{ZR}$ \\
$\mathrm{PS}$ & $\mathrm{ZR}$ & $\mathrm{PS}$ & $\mathrm{PS}$ & $\mathrm{PM}$ & $\mathrm{PL}$ \\
$\mathrm{PL}$ & $\mathrm{PL}$ & $\mathrm{PL}$ & $\mathrm{PL}$ & $\mathrm{PL}$ & $\mathrm{PL}$ \\
& & & & &
\end{tabular}

Figure 7. 25 control rules of FLC.

Inferred output ui is defined by Eq (2), $y_{i}$ depicts ith rule of output variable and is defined as a centered of MF.

$$
\mathrm{u}_{\mathrm{i}}=w_{i} \cdot \mathrm{y}_{\mathrm{i}}
$$

A crisp value is calculated via weighted average defuzzification (this is preferred as simple calculations) Eq (3).

$$
\begin{gathered}
d(k)=d(k-1)+\Delta d(k) \\
\Delta d(k)=\frac{\sum_{i=1}^{4} u_{i}}{\sum_{i=1}^{4} w_{i}}
\end{gathered}
$$


Crisp output depends on the previous amount $\mathrm{d}(\mathrm{k}-1)$ that is updated in each iteration with variation of control module $\mathrm{Dd}(\mathrm{k})$. As much as simple implementation, FLC tuning is a complex procedure and takes place in any particular application. FLC is affiliated with an expert view. This could be obtained through a further sophisticated method. Various methodologies are described for adjusting fuzzy controllers comprising tuning the MF, scaling factors and automatically selecting the defuzzification procedure. In this approach the optimal solution is given by GA. GA optimizes FLC by tuning the MFs according to the following procedure: Each string in the population is represented for each one of MFs. Five MFs for error plus five MFs of change of error together with five MFs for output for each of population of chromosome are shaped by haphazardly creation of strings (Figure 8 ).

GA employs three basic rules summarizes as selection, crossover and mutation for reproducing next generation based on current population. At each sampling time GA adjusts the MFs of error, change of error and control. MFs are selected as Gaussian acc. to Eq (4).

$$
\mu(x)=\exp \left[-\frac{1}{2}\left(\frac{x-a}{\sigma}\right)^{2}\right]
$$

GA adjusts the MF parameters including "a" and " $\sigma$ " and consequence of FLC rules. Five MFs for error, five MFs for change of error and five MFs for duty cycle are considered for each of current or output voltages. So totally, 30 parameters for MFs are defined for optimization procedure. In regard of control rule consequences, 25 parameters for each of controller are considered that yielding to totally 50 consequences for optimization. So the total optimization parameters are equal to $80(30+50)$. these parameters encoded to 8 bit strings equal to 480 bits on chromosome with the architecture of three variables

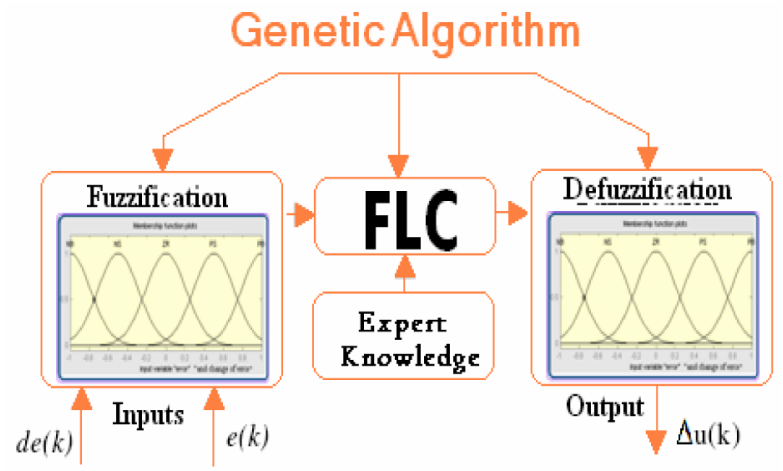

Figure 8. GA optimization procedure for FLC. account for position of center of each MF, value of variance and consequence of FLC rules, Eq (5).

$$
\begin{aligned}
& p_{1}=a_{11}^{1} a_{12}^{1} \ldots a_{1 n}^{1} a_{11}^{2} a_{12}^{2} \ldots a_{1 n}^{2} \sigma_{11}^{1} \sigma_{12}^{1} \ldots \sigma_{1 n}^{1} \sigma_{11}^{2} \sigma_{12}^{2} \ldots \sigma_{1 n}^{2} c_{11}^{1} c_{12}^{1} \ldots c_{1 m}^{1} c_{11}^{2} c_{12}^{2} \ldots c_{1 m}^{2} \\
& \mapsto-F L C 1-\leftarrow \mapsto-F L C 2-\leftarrow \mapsto-F L C 1-\leftarrow \mapsto \mapsto-F L C 2-\leftarrow \mapsto-F L C 1-\leftarrow \mapsto-F L C 2-\leftarrow \\
& \mathrm{n}=15 ; \mathrm{m}=25
\end{aligned}
$$

Linear mapping take places for encoding each of parameters to finite string. This could be achieved via the Eq (6).

$$
g_{q}=G_{q}(\min )+\frac{\left(G_{q}(\max )-G_{q}(\min )\right) * A_{q}}{2^{N}-1}
$$

$\mathrm{G}_{\mathrm{q}}(\min )$ and $\mathrm{G}_{\mathrm{q}}(\max )$ are the lower and upper limits of gens defined by user. Each one of defined parameters in chromosome is encoded to six bits binary string. So totally $80 * 6=480$ bits are defined, $A_{q}$ represents the "N" bit string number and $g_{q}$ is the $\mathrm{q}^{\text {th }}$ parameter which is encoded to bit string for chromosome. Population of 200 chromosomes is randomly considered for optimization procedure. Fitness of each chromosome serves as the guidance for finding the optimized solution. Fitness Value (FV) indicating the Cost that will be minimized and defined according to $\mathrm{Eq}(7)$.

$$
\begin{aligned}
& F V=J=\sum_{h=1}^{25} J_{i} \\
& J_{i}=\int\left(e^{T} e+e^{\cdot T} e \cdot\right) d t \\
& e=V_{o}-V_{\text {ref }} \quad e=I_{o}-I_{\text {ref }}
\end{aligned}
$$

\section{Matlab Simulation}

IUT three layers topology is shown in Figure 9. IUT together with an optimized FLC for controlling the IUT inverter is simulated in Matlab simulink (Figure 10).

The proposed IUT is directly connected to grid. IUT outputs include the three $240 \mathrm{~V}$ AC and 48V DC. PWM inverters of IUT are controlled through the Fuzzy MFs which have been tuned by GA. $48 \mathrm{~V}$ DC load output is shown in Figure 11. Any of the IUT outputs loads can be used as each of the microgrid distributed loads.

IUT output current, IUT output voltage; Grid current and Grid voltage are shown in Figure 12. Grid current is in phase with voltage so the power factor unity is expected and the maximum power is delivered to load.

Grid Total Harmonic Distortion is about $0.01 \%$ that is negligible (Figure 13).

Load current, load voltage $240 \mathrm{~V}$ AC, PWM high frequency switching pattern are depict in Figure 14. Load 


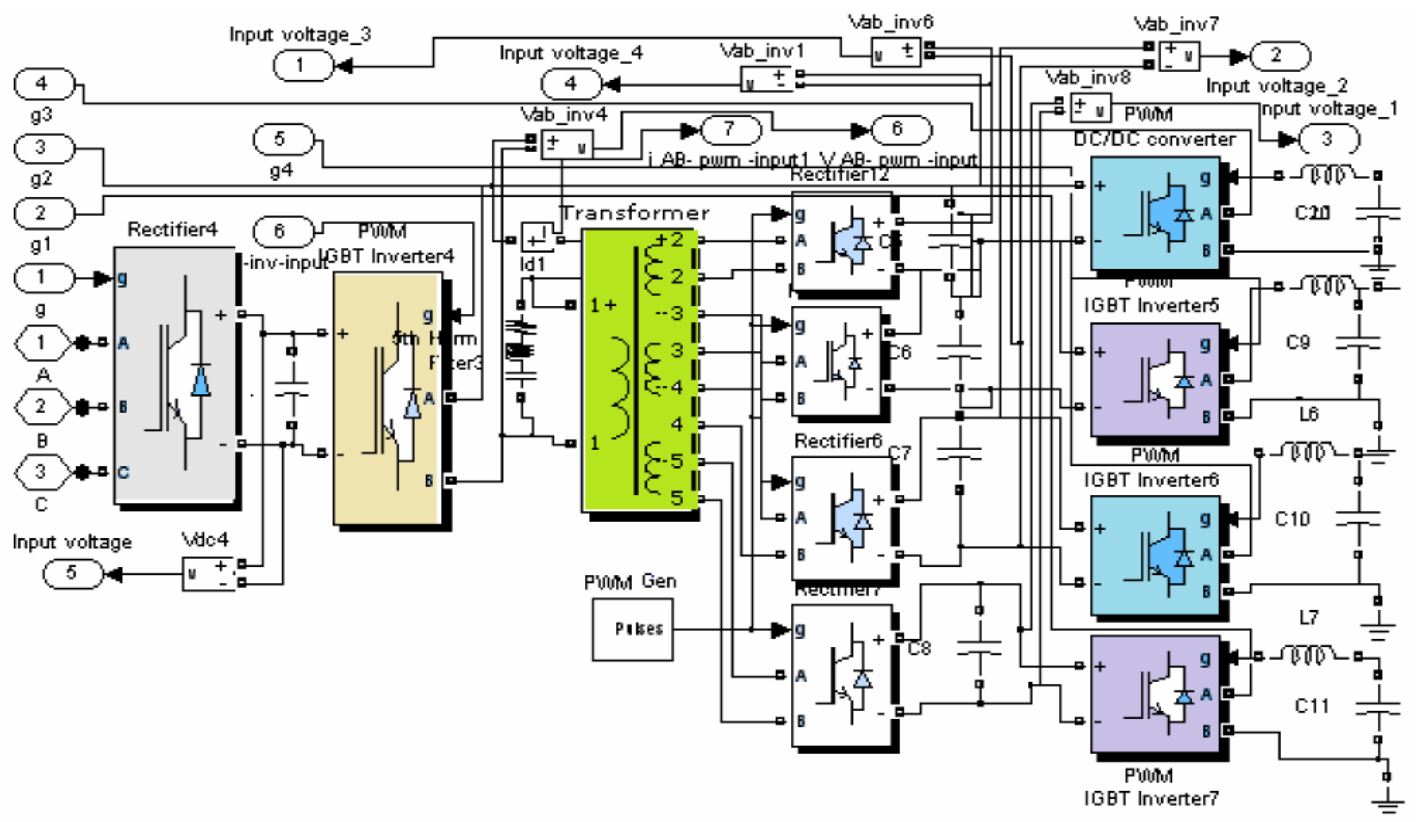

Figure 9. IUT three layers topology.

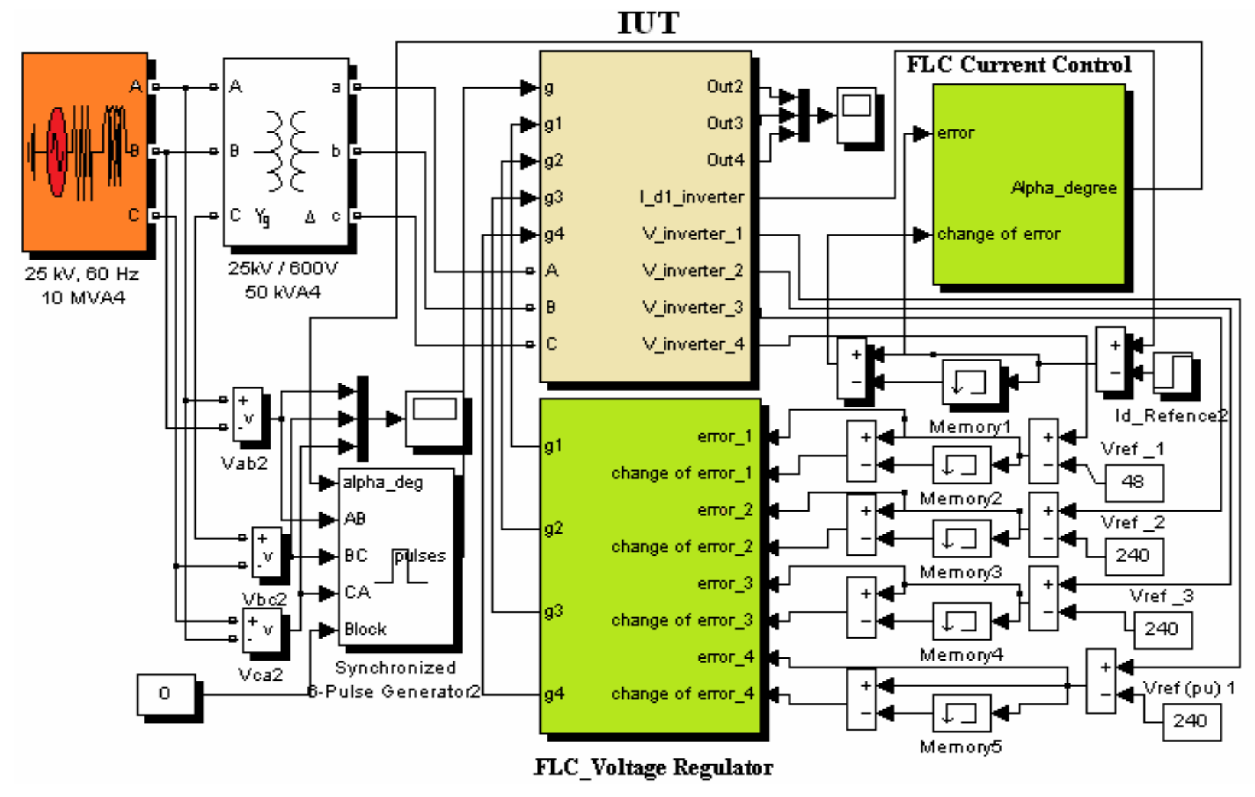

Figure 10. Optimized FLC for controlling the IUT inverters.

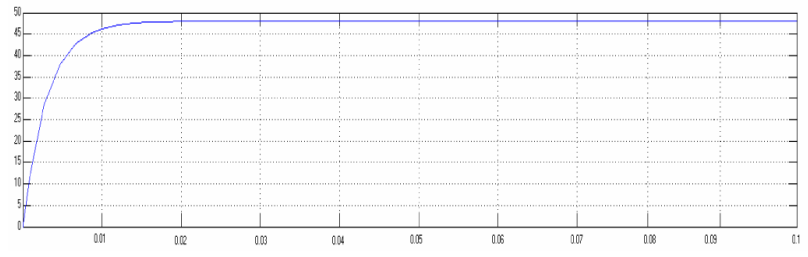

Figure 11. IUT output for the disributed loads (a) DC output $48 \mathrm{~V}$. current and voltage are in phase with each other so the maximum power is delivered to the distributed load of microgrid.

\section{Conclusion}

This research emerges the new approach in using the Intelligent Universal Transformer (IUT) as an intelligent 

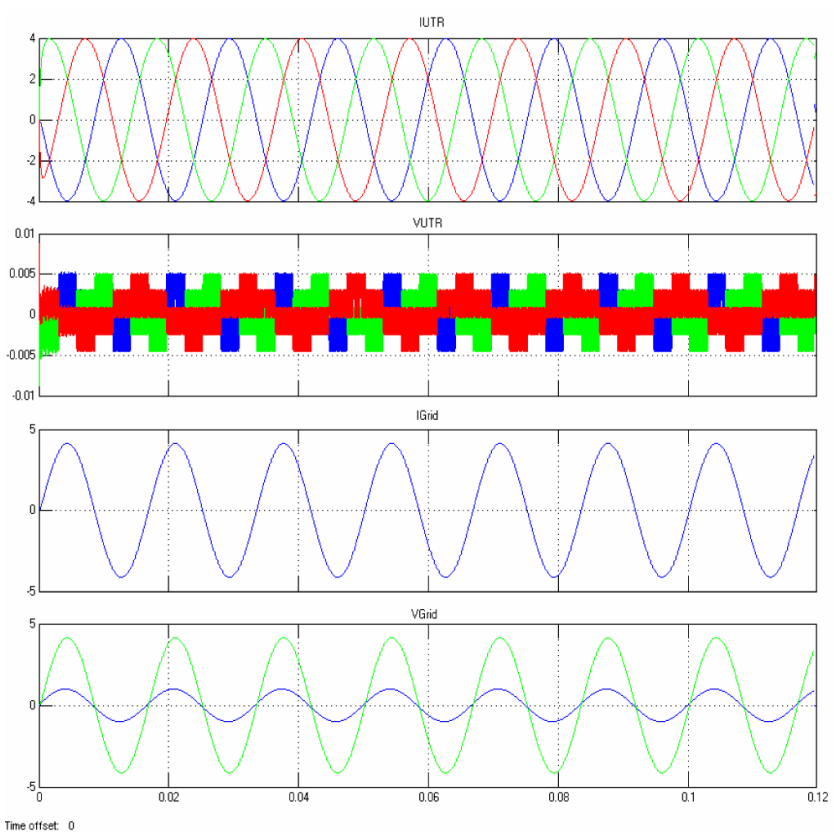

Figure 12. IUT output current, IUT output voltage, Grid current, Grid Voltage.
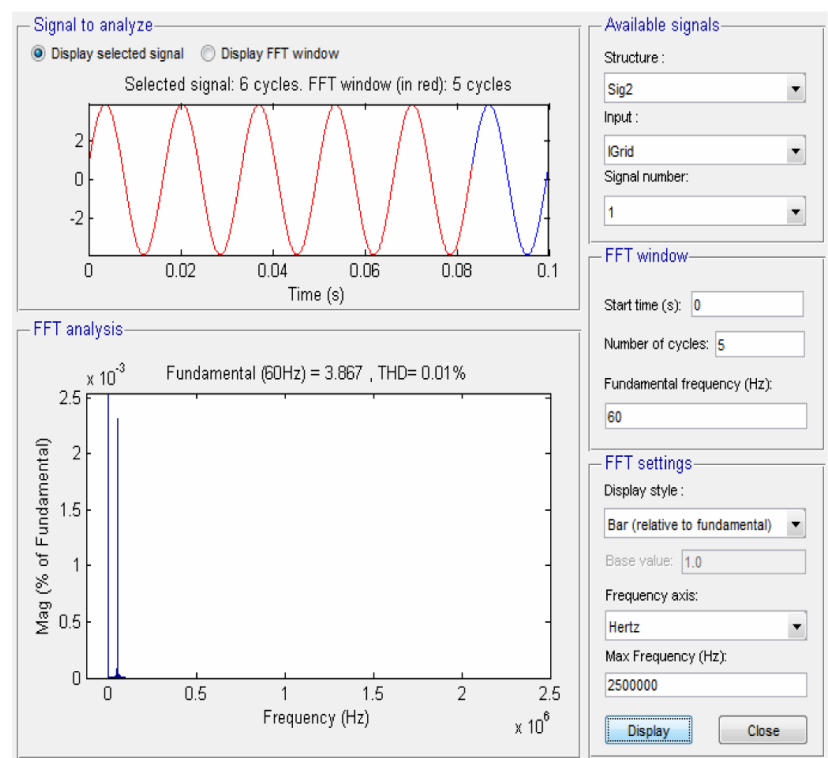

Figure 13. Grid THD : $0.01 \%$.

device for integrating the renewable resources to power utility and presents the empowered strategy in using the GA for adjusting the MFs of FLC within an optimum solution to cope with the system nonlinearity. FLC is extremely helpful in contrast to conventional Fuzzy Logic Controller which uses the expert knowledge for performing the input-output MFs. The moderated IUT topology provides the optional voltage outputs as $48 \mathrm{~V}$ DC, $240 \mathrm{~V}$
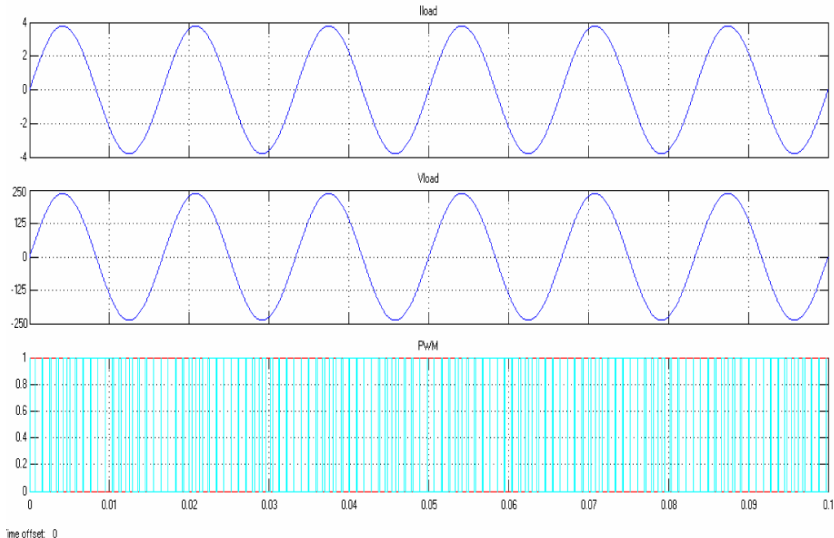

Figure 14. Load current, load voltage 240 VAC, PWM pattern.

AC $60 \mathrm{HZ}$ and $240 \mathrm{~V}$ AC $400 \mathrm{HZ}$. IUT drives many benefits like DC and multiple frequency options, capability of performing three phases output from a single phase input, power quality enhancement, voltage sag correction, unwanted harmonic filtering and oil contamination elimination and ultimately improves interoperability ${ }^{18}$. And in case of integrating the distributed resources and their appreciated loads to the main grid the unity power factor, efficiency enhancement, reliability and robustness are the beneficiary advantage resulted from the intelligent control fashion.

\section{Acknowledgement}

Authors thank the research deputy of Islamic Azad University, Islamshahr branch for their efforts and their financial support of this research.

\section{References}

1. Jegathesan V. Genetic Algorithm Based Solution In PWM Converter Switching For Voltage Source Inverter Feeding An Induction Motor Drive. AJSTD. 2010; 23(2):45-60.

2. Technical and System Requirements for Advanced Distribution Automation 2004. EPRI Report 1010915. 2004 Jun.

3. Ratanapanachote S. Application of an Electronic Transformer in a Power Distribution System. Texas A\&M University; 2004.

4. McGranaghan M, Goodman F. Technical and System Requirements for Advanced Distribution Automation, 18th International Conference on Electricity Distribution, CIRED; 2005 Jun 6-9; Turin. 
5. Akagi $\mathrm{H}$. The next generation medium voltage power conversion systems. J Chin Inst Eng. 2007.

6. Feasibility Study for the Development of High-Voltage, Low-Current Power Semiconductor Devices., Strategic Science and Technology Project. EPRI Product ID \# 1009516. 2003.

7. Goodman F. Intelligent Universal Transformer Technology Development. EPRI. 2006.

8. Research Plan for Advanced Distribution Automation, General Meeting. IEEE Power Engineering Society; 2005.

9. Pogaku N, Prodanovic M, Green TC. Modeling, analysis and testing of autonomous operation of an inverter-based microgrid. IEEE Trans Power Electron. 2006; 22(2):613-25.

10. Wang D, Mao C, Lu J, Fan S, Peng F. Theory and application of distribution electronic power transformer. Elec Power Syst Res. 2007; 77:219-26.

11. Iman-Eini H, Schanen JL, Farhangi SH, Barbaroux J, Keradec JP. A power electronic based transformer for feeding sensitive loads. IEEE; 2008.

12. Hefner A. Silicon-Carbide Power Devices for High-voltage, high-Frequency Power Conversion, 2007; National Institute of Standards and Technology, Gaithersburg.
13. Aggler D, Biela J, Kolar JW. Solid State Transformer based on Sic JFETs for Future Energy Distribution Systems.

14. Maitra A, Sundaram A, Gandhi M, Bird S, Doss SH. Intelligent Universal Transformer Design and Applications, CIRED 20th International Conference on Electricity Distribution; 2009 Jun 8-11; Prague.

15. Energy and Environmental Economic Inc, Value of Distribution Automation applications prepared; 2007.

16. Ratanapanachote S. Applications of an electronic transformer in a power distribution system. 2004 August; Texas A\&M University.

17. Robbinson MC. Solid state Universal Intelligent Transformer.

18. Lai JS, Maitra A, Mansoor A, Goodman F. Multilevel Intelligent Universal Transformer for Medium Voltage Applications. IEEE Industry Application Conference; 2005.

19. Goodman F. Intelligent Universal Transformer Technology Development. EPRI; 2006.

20. Salam AA, Mohamed A, Hannan MA. Technical Challenges On Microgrids. ARPN Journal of Engineering and Applied Sciences. 2008 Dec; 3(6):64-9. 